\title{
OPEN
}

\section{Harnessing the ambiphilicity of silyl nitronates in a catalytic asymmetric approach to aliphatic $\boldsymbol{\beta}^{3}$-amino acids}

\author{
Sayantani Das ${ }^{1,2}$, Benjamin Mitschke ${ }^{1,2}$, Chandra Kanta De ${ }^{1,2}$, Ingolf Harden ${ }^{\circledR 1}$, Giovanni Bistoni ${ }^{1}$ 1 \\ and Benjamin List ${ }^{1 凶}$
}

\begin{abstract}
Nitronate anions, formally generated by $\alpha$-deprotonating the corresponding nitroalkanes, are highly nucleophilic and versatile intermediates in many carbon-carbon bond-forming reactions. In contrast, the corresponding silyl nitronates are ambiphilic and react, at the same carbon atom, with both electrophiles and nucleophiles. However, while their nucleophilicity has been well exploited in catalytic enantioselective reactions with imines and aldehydes, utilizing the electrophilicity of silyl nitronates in asymmetric synthesis has remained elusive. Here we report the facile, efficient and general reactivity of readily available silyl nitronates with silyl ketene acetals, catalysed by highly Lewis-acidic and confined silylium imidodiphosphorimidate catalysts. The products of this reaction, so-called nitroso acetals, are obtained in excellent enantioselectivity and can be easily converted into $\mathbf{N}$-Boc- $\boldsymbol{\beta}^{3}$-amino acid esters in a single step.
\end{abstract}

$\mathrm{N}$ itroalkanes, like carbonyl compounds, upon deprotonation engage in useful (catalytic) transformations with electrophiles, including Henry- and Michael-type reactions. A remarkable reactivity difference, however, arises upon silylation of these anions: whereas a silylated enolate exhibits high nucleophilicity and reacts with various classes of electrophiles in Lewis-acid-mediated, Mukaiyama-type reactions, the silylation of a nitronate anion creates a bi-reactive species, a so-called ambiphile, which can react with both electrophiles and nucleophiles ${ }^{1}$. Silyl nitronates were first described by Ioffe and co-workers in $1974^{2}$ and were subsequently thoroughly investigated by Seebach and Torssell and co-workers ${ }^{3-6}$. Although their distinct properties offer a new reactivity paradigm for nitro compounds, there are few examples of their application in chemical synthesis. Silyl nitronates as nucleophiles (Fig. 1a) were used by Jørgensen and co-workers in enantioselective bis(oxazoline) copper-complex-catalysed Mukaiyama-Henry reactions with $\alpha$-imino esters ${ }^{7}$ and aldehydes ${ }^{8}$, and by Maruoka and co-workers in ammonium bifluoride phase-transfer-catalysed stereoselective Mukaiyama-Michael and Mukaiyama-Henry reactions ${ }^{9,10}$. An amine-catalysed single-electron-transfer-based strategy has also been employed for the $\alpha$-nitroalkylation of aldehydes by MacMillan and co-workers. ${ }^{11}$. A key structural feature of silyl nitronates is the formally negatively charged and highly Lewis-basic oxygen atom. This property makes silyl nitronates susceptible to activation by Lewis acids, in turn converting them into highly reactive electrophiles ${ }^{12,13}$. The phenomenon has been described by Ioffe and co-workers in silicon Lewis-acid-catalysed reactions of mostly cyclic silyl nitronates with silylated and stannylated nucleophiles $^{14-20}$. However, catalytic asymmetric additions of nucleophiles to silyl nitronates are unknown, even though the nitroso acetal products of such processes should be direct precursors for highly valuable products such as $\beta^{3}$-amino acids (Fig. 1b) ${ }^{21}$.

In recent years, progress has been made in the field of asymmetric counteranion-directed silylium Lewis acid catalysis (silylium
ACDC), using carbonyls, imines or Michael acceptors as electrophiles in nucleophilic additions and cycloaddition ${ }^{22-29}$. Given the extraordinary activity of our chiral and confined imidodiphosphorimidate (IDPi) framework and the high oxophilicity of silicon, we envisioned using these catalysts in the asymmetric addition of silyl ketene acetals to silyl nitronates. We were particularly intrigued by this transformation because previously used and privileged acid catalysis motifs, such as phosphoric acids, disulfonimides (DSI) and imidodiphosphates (IDP), failed to give the desired product (Supplementary Table 1).

In this Article we describe the IDPi-catalysed addition of silyl ketene acetals to silyl nitronates. The discovery was facilitated by implementation of a multi-substrate screening approach, enabling rapid and highly stereoselective evaluation of a broad class of substrates as potential precursors to valuable $\beta^{3}$-amino acids. Additionally, we provide a range of multi-gram-scale reactions under practical reaction conditions with catalyst loadings as low as $0.1 \mathrm{~mol} \%$, and demonstrate complete catalyst control in diastereoselective addition reactions when using substituted silyl ketene acetals. Finally, we observed and characterized the key intermediate ion pair consisting of the activated bis(siloxy)iminium cation and the catalyst anion by two-dimensional NMR spectroscopy.

\section{Results}

Reaction optimization and multi-substrate screening. At the onset of this study, we explored the reaction of benzyl-substituted silyl nitronate $\mathbf{1 b}$ with tert-butyldimethylsilyl (TBS) ketene acetal 2a mediated by a range of different IDPi catalysts 3 . Although we could quickly identify IDPi $\mathbf{3 e}$ as a suitable catalyst for this reaction, furnishing the desired product with an excellent e.r. of 93:7, unfortunately a notable decrease in enantioselectivity was observed for several other silyl nitronate substrates. Realizing this rather common problem of single-substrate optimizations, we set out to use a multi-substrate screening approach to quickly obtain information about the specific catalyst structure required for each class

${ }^{1}$ Max-Planck-Institut für Kohlenforschung, Mülheim an der Ruhr, Germany. ${ }^{2}$ These authors contributed equally: Sayantani Das, Benjamin Mitschke,

Chandra Kanta De. $\otimes_{\text {e-mail: list@kofo.mpg.de }}$ 


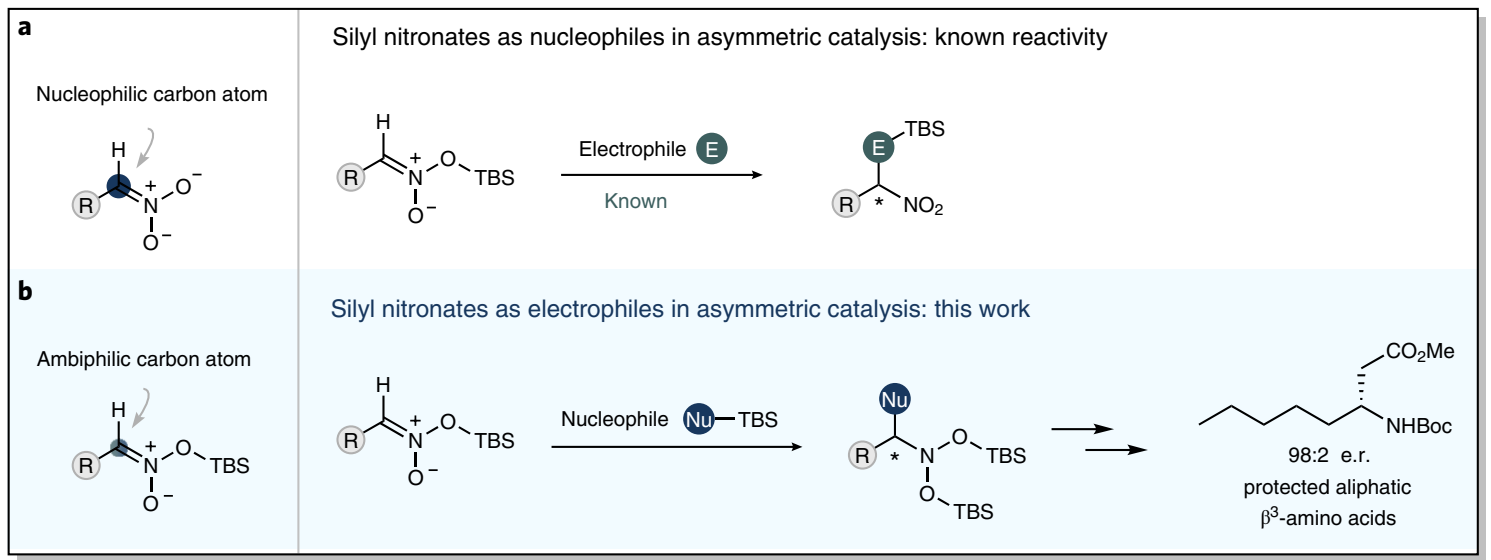

Fig. 1 | Outline of this study. a, Well-established nucleophilic reactivity of silyl nitronates. $\mathbf{b}$, This work: electrophilic activation of silyl nitronates in asymmetric synthesis as an entry point to aliphatic $\beta^{3}$-amino acid esters.
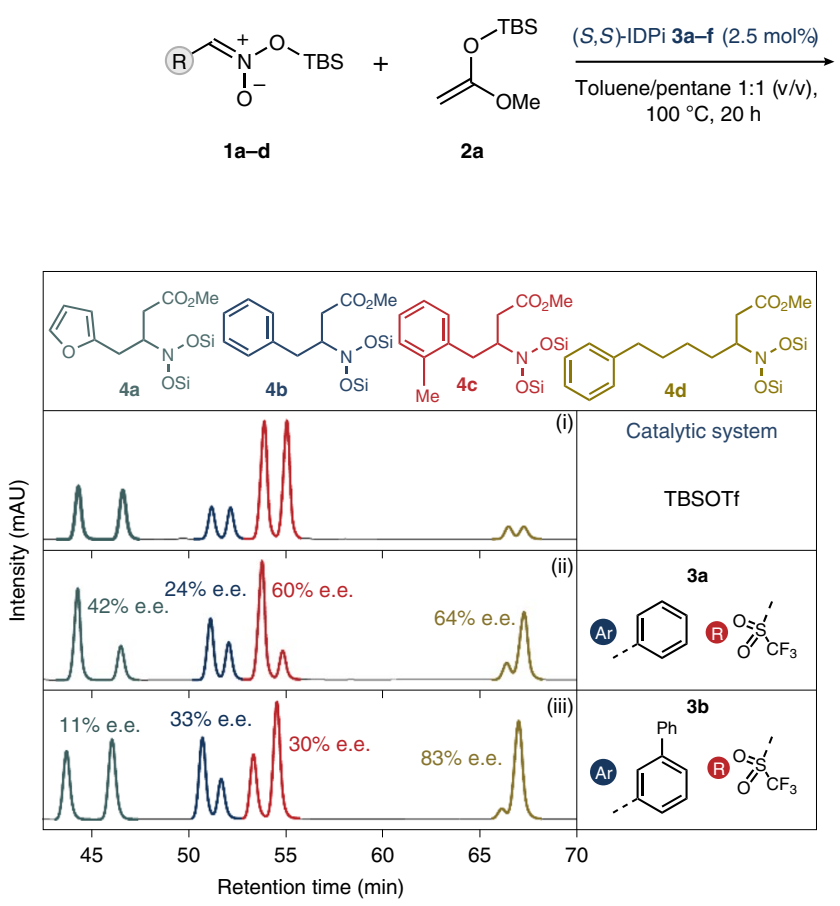

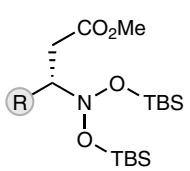

$4 a-d$

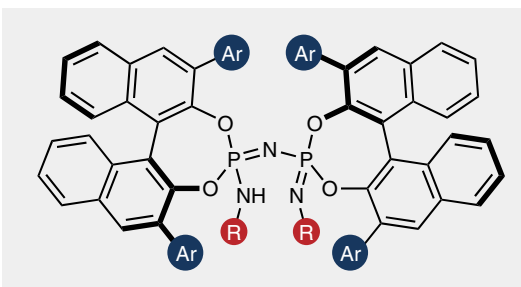

3c, 3e, $3 \mathbf{f}$

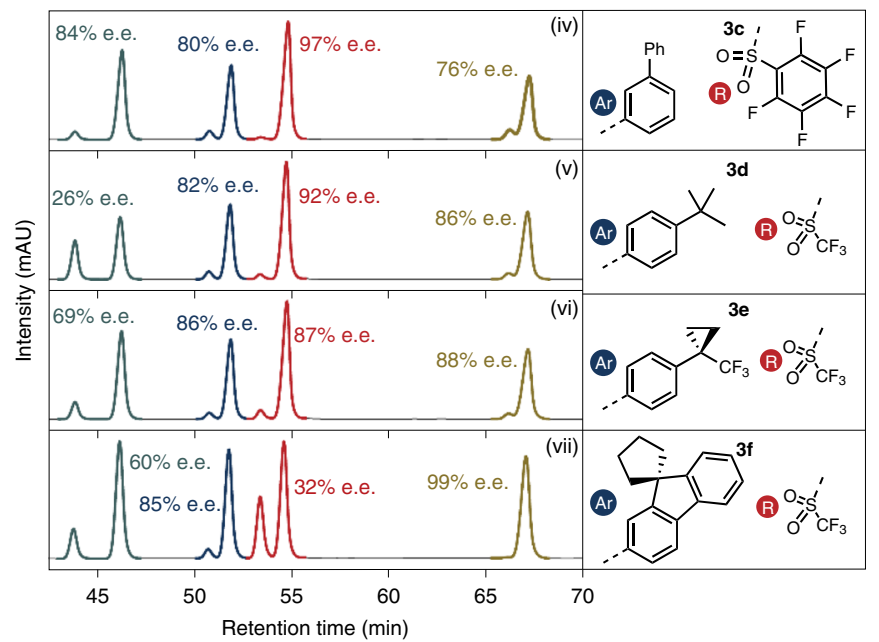

Fig. 2 | Multi-substrate screening approach. HPLC chromatogram of the stereoisomeric product mixture. Reactions were conducted on the 0.025 mmol scale at $-100^{\circ} \mathrm{C}$ for $20 \mathrm{~h}$. Full conversion for all silyl nitronates was determined by ${ }^{1} \mathrm{H}$ NMR spectroscopy. $\mathrm{HPLC}$ method: $\mathrm{OJ}-3 \mathrm{R}, 60: 40$ acetonitrile/ $\mathrm{H}_{2} \mathrm{O}$,

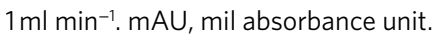

of substrates ${ }^{30,31}$. As a first step, we established a chromatographic product assay to screen several structurally distinct nitronates. The four representative substrates 1a-d were selected according to the nature and size of the substituents (benzylic, substituted benzylic, heteroaromatic benzylic, aliphatic), and to enable product separation on a single chiral stationary high-performance liquid chromatography (HPLC) phase. After establishing a reliable HPLC assay, we subjected our substrate pool to silyl ketene acetal $\mathbf{2 a}$ in single reaction vessels with each of the organocatalysts $\mathbf{3 a}-\mathbf{f}$ (Fig. 2). Simple phenyl-substituted IDPi 3a gave only low to moderate enantioselectivity with all substrates. Notably, while introducing phenyl substitution in the 3-position (3b) showed only small changes in the observed enantioselectivity (with an e.r. switch of product 4c), a change in the sulfonamide core of the catalyst from triflyl to pentafluorophenylsulfonyl (3c) delivered a drastic increase in enantioselectivity for all substrates. In particular, the 2-methyl-substituted phenyl- and furanyl-based systems 4a (92:8 e.r.) and 4c (99.5:0.5 e.r.) gave very high enantioselectivity. Although catalyst $\mathbf{3 e}$ had already been identified as the best candidate for the enantioselective conversion of silyl nitronate $\mathbf{1 b}$, no clear trend was observed for the reaction of aliphatic chain-substrate $1 \mathbf{d}$. Remarkably, spiro-fluorenyl catalyst $\mathbf{3 f}$, previously introduced by our group ${ }^{25}$, could deliver product $\mathbf{4 d}$ with almost complete enantiocontrol (99.3:0.7 e.r.). 


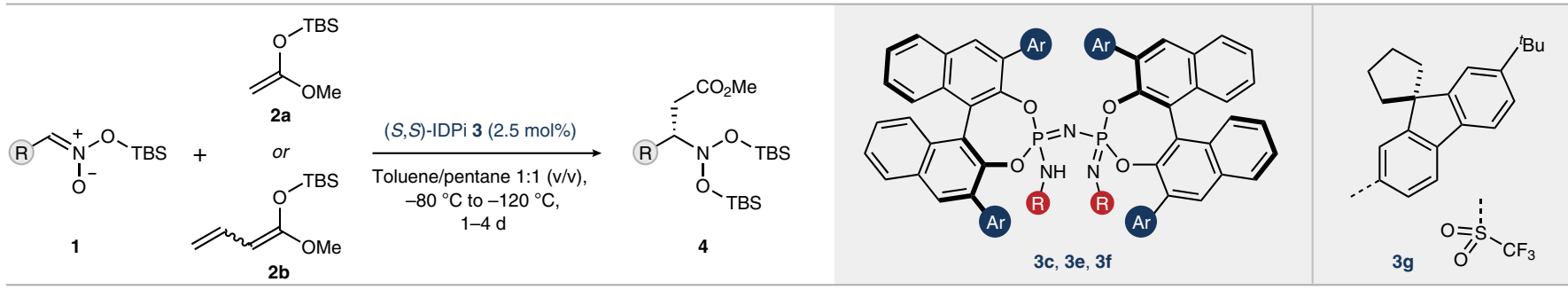

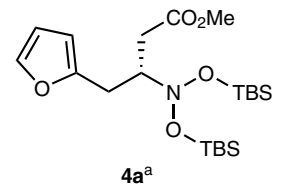

93\%, 95:5 e.r.<smiles>CCON(OC)C(CC(C)=O)Cc1ccccc1</smiles>

$4 b^{b}$ 91\%, 95.5:4.5 e.r.<smiles>CCON(OC)C(CCc1cc(C)cc(C)c1)CC(C)=O</smiles>

$4 \mathbf{g}^{\mathrm{b}}$ $\mathbf{4 f}^{\mathrm{a}}$ 91\%, $95: 5$ e.r.<smiles>CCCCCON(OCCCC)[C@H](CC(C)=O)Cc1ccccc1C</smiles>

$4 c^{a}$

74\%, 97.5:2.5 e.r.<smiles>CCCCCCCCCCCCCCCCCCc1ccccc1</smiles>

$4 \mathbf{d}^{\mathrm{c}}$
$\overbrace{\substack{N^{-} \\ O_{-T B S}}}^{\mathrm{O}_{\text {TBS }}}$

$4 e^{a}$

$70 \%, 95.5: 4.5$ e.r.

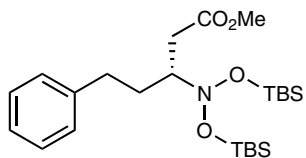

$\mathbf{4 h}^{\mathrm{c}}$ $83 \%$, 94.5:5.5 e.r.

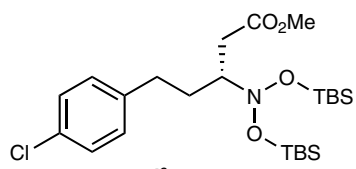

$4 i^{\mathrm{c}}$

98\%, 98.5:1.5 e.r.<smiles>CCCCCCCCCCCC[C@H](CCc1ccc(Br)cc1)N(OCCCC)OC(C)=O</smiles>

$4 j^{\mathrm{c}}$

89\%, 96.4:3.6 e.r.

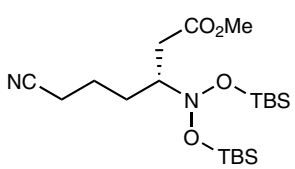

$4 \mathrm{~m}^{\mathrm{c}}$ $89 \%, 95: 5$ e.r.

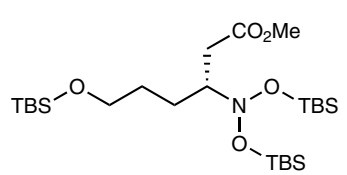
$4 n^{c}$ $84 \%, 98.2: 1.8$ e.r.

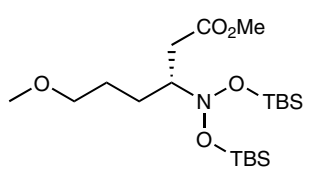

$40^{c}$

$89 \%, 97: 3$ e.r.

$90 \%, 95.7: 43$ e.r. $^{c}{ }^{d}$<smiles>CCCCCCCCCON(OCCCC)[C@@H](CCCCCC(=O)NCc1ccccc1)CC(C)=O</smiles>

$4 q^{c}$ 53\%, 95.8:4.2 e.r.

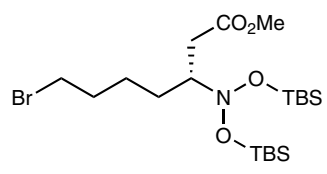

$4 r^{c}$

$4 \mathbf{p}^{c}$
$89 \%,>99: 1$ e.r.<smiles>C=CCC[C@H](CC(C)=O)N(OC(C)C)OC(C)(C)C</smiles>

$88 \%,>99: 1$ e.r.<smiles>C#CCCC[C@@H](CC(C)=O)N(OC(C)(C)C)OC(C)(C)C</smiles>

89\%, 99:1 e.r.
$84 \%, 97.5: 2.5$ e.r.<smiles>CON(OC)C(CCCCCI)COC(C)=O</smiles>

$4 s^{c}$ 96\%, 97.3:2.7 e.r.

53\%, 97.4:2.6 e.r.<smiles>CCCCC[C@@H](CC(C)=O)N(OC(C)(C)C)OC(C)(C)C</smiles>

$4 t^{\mathrm{C}}$

83\%, 99:1 e.r.<smiles>CC(=O)ON(OC(C)(C)C)[C@@H](CC(C)C)C(C)C</smiles>

70\%, 96.9:3.1 e.r.<smiles>CC(=O)CCCCC[C@H](CC(C)=O)N(OCC(C)(C)C)OC(C)(C)C</smiles>

$71 \%$, $98: 2$ e.r.<smiles>CCCCCON(OC(C)(C)C)[C@@H](C/C=C/C(C)=O)Cc1ccccc1</smiles>

$>20: 1 \gamma: \alpha, 15.6: 1$ d.r. 84\%, 99.5:0.5 e.r.

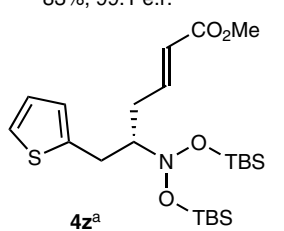

$>20: 1 \gamma: \alpha, 5.6: 1$ d.r. $94 \%,>99: 1$ e.r.

Fig. 3 | Substrate scope. Reaction of silyl nitronates $\mathbf{1}$ with silyl ketene acetal $\mathbf{2 a}$ or $\mathbf{2} \mathbf{b}$ using IDPi catalysts $\mathbf{3}$. Reactions were conducted on the 0.1 mmol scale; isolated yields. ${ }^{a}$ Catalyst $\mathbf{3 c},{ }^{b}$ catalyst $\mathbf{3 e},{ }^{\mathrm{c}}$ catalyst $\mathbf{3} \mathbf{6},{ }^{\mathrm{d}}$ catalyst $\mathbf{3 g}$.

Substrate scope. As a result, catalysts $\mathbf{3 c}, \mathbf{3 e}$ and $\mathbf{3 f}$ were selected for a broader substrate scope study (Fig. 3). Using a wide range of nitronates $(\mathbf{1} \mathbf{a}-\mathbf{x})$ separately gave results that corresponded well to those obtained in the multi-substrate experiments, consistently providing high yields and enantioselectivities except for nitronate $\mathbf{1 1}$.

Irrespective of sterics, chain length, electronics or substitution patterns, nitroso acetals $\mathbf{4 b}$-j jere formed in very good yields and with excellent enantioselectivities. Fortunately, heteroaromatic substituents that could potentially also coordinate to the Lewis acid also cleanly formed the desired products $\mathbf{4 a}, \mathbf{4 k}$ and $\mathbf{4 1}$ with excellent enantioselectivity.

Catalyst $3 f$ turned out to be broadly applicable for a wide range of functionalized aliphatic nitronates and delivered products with excellent yields and enantioselectivities $(\mathbf{4 m}-\mathbf{x})$. This reaction is well suited for substrates containing additional Lewis-basic functional groups such as a nitrile, a silyl ether, a methyl ether, methyl ester and an amide, forming the corresponding products in moderate to good yields and with extremely high enantioselectivities $(\mathbf{4 m}-\mathbf{q})$. Ester-functionalized silyl nitronate $\mathbf{1 p}$ gave product $4 \mathrm{p}$ exclusively and, as in case of nitrile $1 \mathrm{~m}$, with no evidence for any Mukaiyama-Claisen-type reactivity. Substrates with aliphatic halide (1r and 1s), aliphatic unbranched and branched alkane (1t and $\mathbf{1 u}$ ), terminal olefin (1v) and terminal alkyne (1w) functionalities all furnish the corresponding nitroso acetals in good yields and with excellent levels of enantioselectivity $(\mathbf{4 r}-\mathbf{w})$. Remarkably, even a substrate possessing a ketone functional group known to readily undergo Mukaiyama aldol reactions under similar conditions ${ }^{24}$ gave exclusively the desired nitroso acetal product $\mathbf{4 x}$ in good yield and with excellent enantioselectivity. Moreover, we could expand the nucleophile scope of our reaction. When nitronates $\mathbf{1 b}$ and $\mathbf{1} \mathbf{k}$ were reacted with vinylogous silyl ketene acetal $\mathbf{2 b}$, the corresponding 
<smiles>CCCCCCCCCCON(OC(C)=O)[C@@H](CCc1ccccc1C)Cc1ccccc1</smiles>

4c, $2.2 \mathrm{~g}$ (95\%), 96.3:3.7 e.r.

$0.5 \mathrm{~mol} \% 3 \mathrm{c},-70^{\circ} \mathrm{C}, 24 \mathrm{~h}$

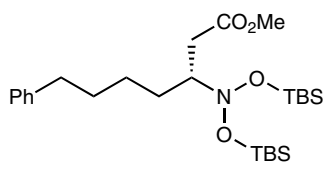

4d, $2.3 \mathrm{~g}(95 \%), 97.4: 2.6$ e.r.

$0.1 \mathrm{~mol} \% 3 \mathbf{3 f},-40^{\circ} \mathrm{C}, 6 \mathrm{~h}$

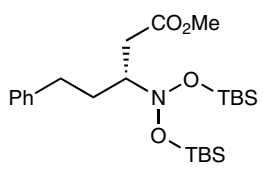

4h, $2.2 \mathrm{~g}(94 \%), 97.9: 2.1$ e.r.

$0.1 \mathrm{~mol} \% 3 \mathrm{ff},-40^{\circ} \mathrm{C}, 15 \mathrm{~h}$

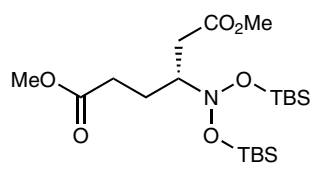

4p, $2.1 \mathrm{~g}(93 \%), 97.5: 2.5$ e.r.

$0.5 \mathrm{~mol} \% 3 \mathbf{3 f},-40^{\circ} \mathrm{C}, 15 \mathrm{~h}$

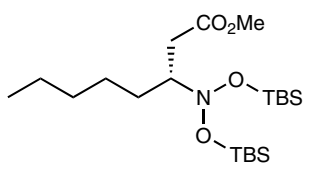

4t, $2.0 \mathrm{~g}(94 \%)$, 98.3:1.7 e.r. $0.1 \mathrm{~mol} \% 3 \mathbf{3 f},-40^{\circ} \mathrm{C}, 6 \mathrm{~h}$

Fig. 4 | Upscaling. Demonstration of practical reaction conditions for the synthesis of several nitroso acetals on a multi-gram scale.

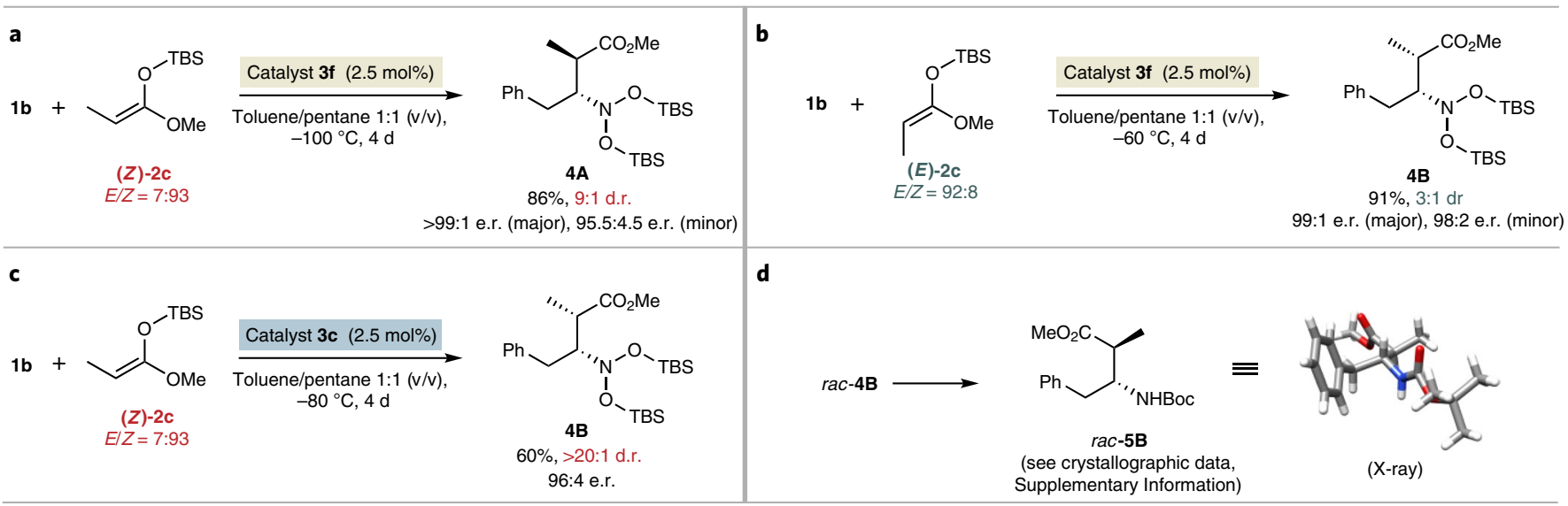

Fig. 5 | Diastereoconservation and diastereodivergence. Reactions of silyl ketene acetal $\mathbf{2} \mathbf{c}$ with nitronate $\mathbf{1 b}$ using IDPi catalysts $\mathbf{3}$. Reactions conducted on the $0.1 \mathrm{mmol}$ scale; isolated yields.

nitroso acetal products (4y and $\mathbf{4 z}$ ) were obtained in good yield and with excellent enantio- and $\gamma$-regioselectivity.

Practicability and diastereoselective variant. To demonstrate the robustness and scalability of this method, nitroso acetals $\mathbf{4 c}, \mathbf{4 d}$, $\mathbf{4 h}, \mathbf{4 p}$ and $\mathbf{4 t}$ were synthesized on a multi-gram scale starting from unpurified silyl nitronates in the presence of catalyst loadings as low as $0.1 \mathrm{~mol} \%$ at $-40^{\circ} \mathrm{C}\left(-70^{\circ} \mathrm{C}\right.$ for $\left.4 \mathrm{c}\right)$. The reactions were completed within $6-24 \mathrm{~h}$ and the products were obtained with excellent yield and enantioselectivities (Fig. 4).

To investigate diastereoselective variants of our reaction, we reacted nitronate $\mathbf{1 b}$ with ketene acetal $(Z)-2 \mathbf{c}(7: 93 \mathrm{E} / Z)$ in the presence of catalyst $3 \mathbf{f}$. The corresponding anti-nitroso acetal $4 \mathrm{~A}$ was obtained with a 9:1 d.r. and excellent enantioselectivity of $>99: 1$ e.r. (Fig. $5 \mathrm{a}$ ).

Using the isomeric silyl ketene acetal $(E)-2 c(92: 8 E / Z)$ preferentially led to the corresponding syn-nitroso acetal $4 \mathrm{~B}$ with 3:1 d.r. and 98:2 e.r. (Fig. 5b). Notably, when nitronate $\mathbf{1 b}$ was reacted with silyl ketene acetal $(Z)-2 \mathrm{c}$ (providing the anti-product with IDPi 3f) in the presence of a different catalyst $\mathbf{3 c}$, syn-diastereoisomer $\mathbf{4 B}$ was obtained exclusively (>20:1 d.r.) and with high enantioselectivity (Fig. 5c). The relative configuration of $s y n-4 \mathbf{B}$ was assigned from the X-ray crystal structure of derivative 5B (Fig. 5d). A possible interconversion of $(Z)-\mathbf{2 c}$ and $(E)-\mathbf{2 c}$ has been excluded in several control experiments. Accordingly, we have developed a diastereoconservative variant in which the diastereoselectivity of the product directly correlates with the structure of the silyl ketene acetal and, more interestingly, a completely catalyst-controlled reaction enabling access to either the syn- or the anti-product with excellent stereoselectivity solely by choice of the respective IDPi. While we currently have no explanation for this remarkable phenomenon, further mechanistic investigations are ongoing and will be reported in due course.
With a simple and general methodology at hand, we aimed at exploring the utility of our nitroso acetal products (Fig. 6). As a result of the observed high substrate tolerance, a broad range of both novel and known $\beta^{3}$ - and $\beta^{2,3}$-amino acids, which are of great interest for medicinal chemistry and pharmaceutical applications, should become available with excellent levels of enantiomeric excess via reduction ${ }^{32-35}$. Interestingly, previous reports on the reduction of nitroso acetals required Raney nickel as catalyst in combination with a fluoride source ${ }^{17,36}$. Fortunately, after investigating several reaction conditions, we found that simply subjecting our reaction products to catalytic amounts of palladium on activated carbon to an atmosphere of hydrogen gas in the presence of $\mathrm{Boc}_{2} \mathrm{O}$ at room temperature or $40^{\circ} \mathrm{C}$ exclusively delivered the desired $\mathrm{N}$-Boc-protected $\beta$-amino acid methyl esters without notable erosion of enantiopurity. Following this protocol, nitroso acetals $4 \mathbf{d}$ and $4 \mathbf{t}$ were directly transformed into the corresponding $N$-Boc-protected $\beta$-amino acid methyl esters $\mathbf{5 d}$ and $\mathbf{5 t}$. Our methodology is also well suited to the gram-scale synthesis of such compounds, giving rapid access to large amounts of product 5t from commercially available 1-nitrohexane in three steps with just one purification. This $\beta$-amino acid methyl ester $5 \mathbf{t}$ was used as the starting point for further applications towards potentially bioactive compounds. Exhaustive reduction of the ester moiety provided primary alcohol 6, and Boc deprotection followed by cyclization in the presence of LDA gave access to $\beta$-lactam 7 in $89 \%$ over two steps with 95:5 e.r. Hydrolysis of the methyl ester to the free carboxylic acid $\mathbf{8}$ set the stage for a peptide synthesis that eventually resulted in tripeptide $\mathbf{1 0}$ bearing our newly synthesized $\mathrm{D}-\beta$-amino acid residue.

Mechanistic studies. Inspired by previous mechanistic studies conducted by Mayr, Ioffe and co-workers ${ }^{37}$, we were keen on following the interaction of our activated silylium IDPi catalyst $\mathbf{3 e}$ 

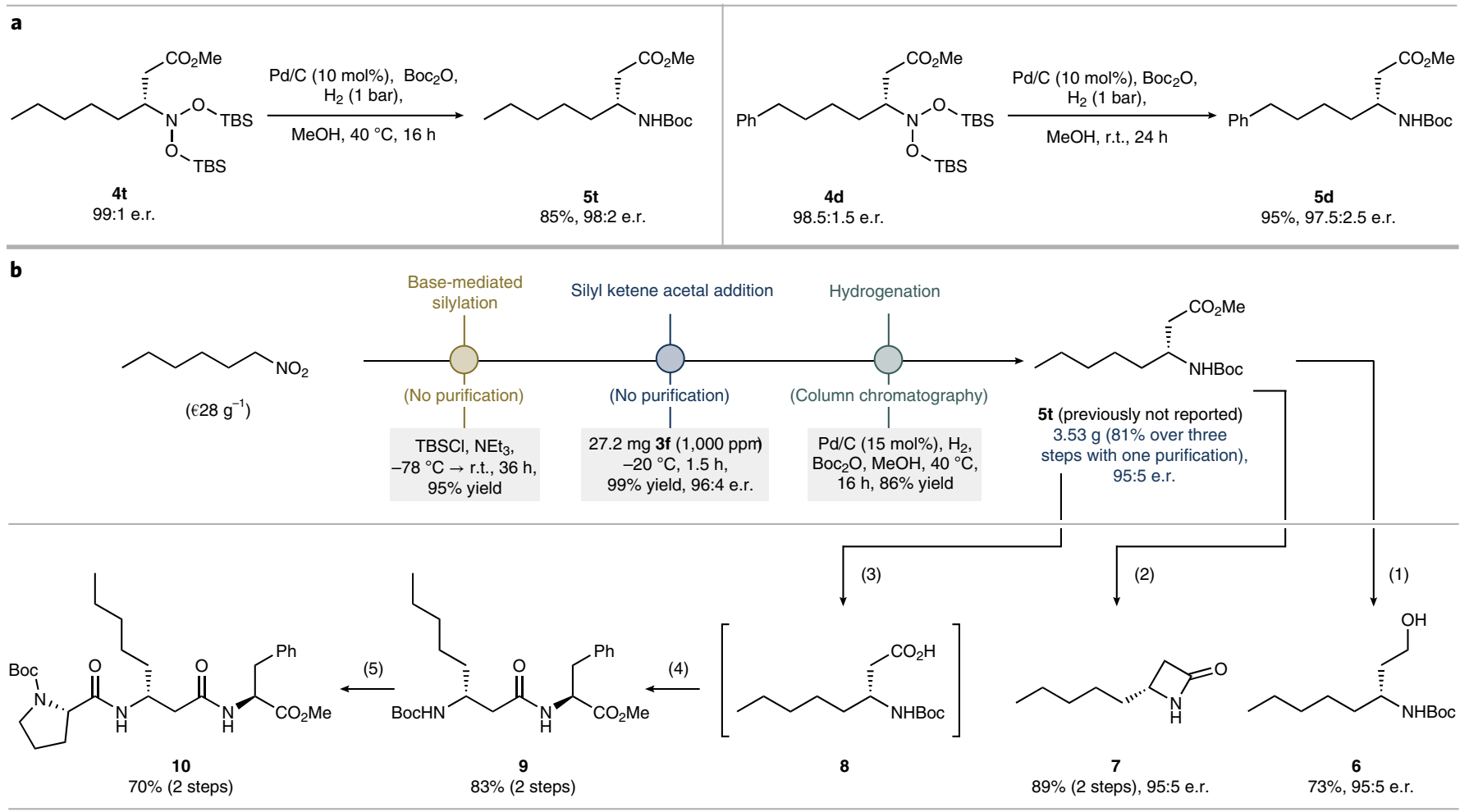

Fig. $\mathbf{6}$ | Further functionalizations of nitroso acetal products $\mathbf{4 d}$ and $\mathbf{4 t}$. $\mathbf{a}$, Reduction of compounds $\mathbf{4 d}$ and $\mathbf{4 t}$ to the corresponding $N$-Boc $\beta$-amino acid esters $\mathbf{5} \mathbf{d}$ and $\mathbf{5 t}$. $\mathbf{b}$, Practical multi-gram three-step sequence from 1-nitrohexane to $\beta$-amino acid ester $\mathbf{5 t}$ followed by downstream modifications: (1) $\mathrm{NaBH}_{4}, \mathrm{MeOH}, \mathrm{THF}, 65^{\circ} \mathrm{C}, 2 \mathrm{Oh}$, (2) (step i) TFA, $\mathrm{CH}_{2} \mathrm{Cl}_{2}, 25^{\circ} \mathrm{C}, 20 \mathrm{~min}$, (step ii) LDA, THF, $-78^{\circ} \mathrm{C}, 3 \mathrm{~h}$; (3) $\mathrm{NaOH}, \mathrm{MeOH}, 0 \rightarrow 25^{\circ} \mathrm{C}, 2 \mathrm{~h}$; (4) Phe-OMe.HCl, HATU, (i-Pr) ${ }_{2} \mathrm{NEt}, \mathrm{CH}_{2} \mathrm{Cl}_{2}, 25^{\circ} \mathrm{C}, 16 \mathrm{~h}$; (5) (step i) TFA, $\mathrm{CH}_{2} \mathrm{Cl}_{2}, 25^{\circ} \mathrm{C}, 20$ min, (step ii) Boc-Pro-OH, HATU (hexafluorophosphate azabenzotriazole tetramethyl uronium), $\mathrm{NEt}_{3}, \mathrm{CH}_{2} \mathrm{Cl}_{2}, 25^{\circ} \mathrm{C}, 16 \mathrm{~h}$.

with silyl nitronate $\mathbf{1 b}$ via NMR spectroscopy, with the hope of possibly characterizing the critical ion pair intermediate (Fig. 7). As a first step, acid catalyst $3 \mathbf{e}$ was activated with an excess of tert-butyldimethyl(2-methylallyl)silane to afford silylium species 3e-TBS (Fig. 7, IDPi 3e versus IDPi 3e-TBS). Notably, four sets of doublet can be observed, most likely caused by $C_{2}$ symmetry-breaking coordination of the silylium ion to both of the diastereotopic oxygen atoms of the sulfonamide portion. After adding 0.5 equiv. of silyl nitronate $\mathbf{1 b}$ to silylated IDPi $\mathbf{3 e - T B S}$ (Fig. 7 , step 2), a singlet at $-10.1 \mathrm{ppm}$ in the ${ }^{31} \mathrm{P}$ NMR with a $1: 1$ ratio relative to the remaining doublet appears. Comparison of the ${ }^{1} \mathrm{H}$ NMR spectrum of the reaction mixture with isolated silyl nitronate $\mathbf{1 b}$ shows a prominent downfield shift of the nitronate $\alpha$-proton (from $6.31 \mathrm{ppm}$ to $7.59 \mathrm{ppm}$ ) that was confirmed by two-dimensional NMR spectroscopy (see Supplementary Fig. 5). Interestingly, splitting of the doublet of the benzylic protons in free $\mathbf{1} \mathbf{b}$ to one pair of diastereotopic protons in the reaction mixture makes interaction with the chiral catalyst become evident.

Based on the spectroscopic evidence, it is reasonable to assume that the newly formed species can be characterized as the ion pair resulting from silyl transfer of the catalyst to the silyl nitronate, giving the IDPi anion complex of the highly activated bis(siloxy) iminium ion (3e-TBS-1b). Upon addition of 0.5 equiv. of $\mathbf{1 b}$, the remaining signals of the silylated IDPi 3e-TBS cleanly converged to the singlet of the ion pair (Fig. 7, step 3). Even in the presence of an excess of silyl nitronate $\mathbf{1 b}$, no shift of the ion pair signal was observed. Additionally, the ${ }^{1} \mathrm{H}$ NMR spectrum of this reaction mixture clearly indicated the presence of two distinct species without notable exchange between the ion pair 3e-TBS-1b and the silyl nitronate $\mathbf{1 b}$. This points towards the crucial influence of the
IDPi anion in the stabilization of the activated bis(siloxy)iminium ion as a prerequisite for both high reactivity and enantioselectivity in the subsequent nucleophilic addition of the silyl ketene acetal. Additionally, to the best of our knowledge this is the first spectroscopic characterization in silylium ACDC of an ion pair consisting of a silylated, cationic substrate and the chiral catalyst counteranion.

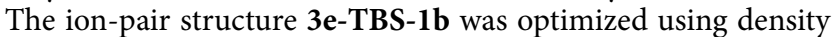
functional theory (DFT). A large number of conformers was initially generated using a semi-empirical method, and the low-energy structures were refined at the PBE-D3/def2-svp level of theory. The most stable ion-pair conformer (Fig. 7c) features a hydrogen bond between the $\mathrm{C}-\mathrm{H}$ group of the nitronate $\mathbf{1 b}$ and an oxygen atom of a sulfonyl group of the catalyst anion. A detailed description of the computational protocol can be found in the Supplementary Information (Supplementary Fig. 7).

\section{Conclusion}

We present the facile and general catalytic asymmetric addition of silyl ketene acetals to silyl nitronates. These reactions are catalysed by strong and confined silylium-based Lewis acids that activate the ambiphilic substrate. This, in turn, generates a highly electrophilic bis(siloxy)iminium ion, which could be characterized spectroscopically. We were able rapidly to identify a collection of suitable catalysts for this transformation using a multi-substrate screening approach, which enabled a broad range of silyl nitronates to readily engage in this reaction, furnishing the nitroso acetal products in almost quantitative yields and with excellent enantioselectivity. We showed the vital influence of our acids in controlling the diastereomeric outcome of the reaction simply by using a different catalyst substitution pattern. Moreover, this approach could be advanced 


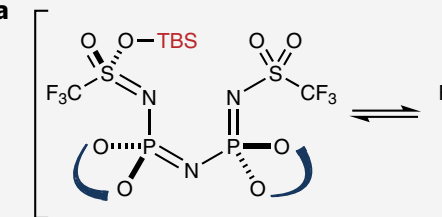

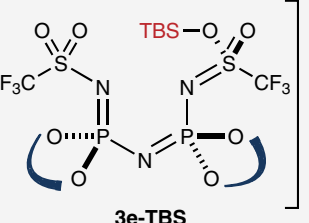
3e-TBS
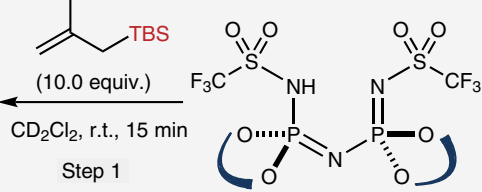

$3 e$

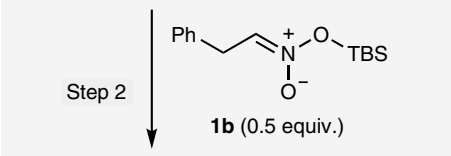

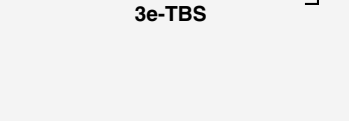

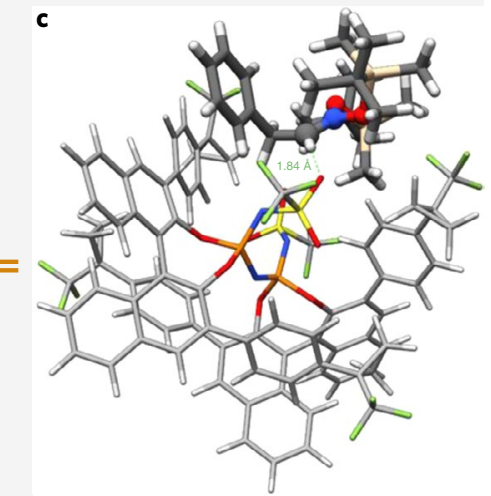

DFT structure of $\mathbf{3 e - T B S - 1 b}$ b
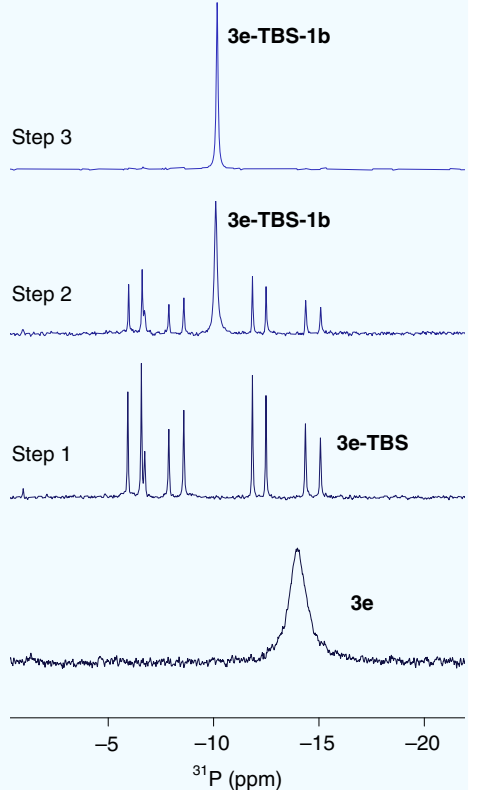

3e-TBS ( 0.5 equiv.)

Fig. 7 | NMR characterization of the ion pair between catalyst 3e and nitronate $\mathbf{1 b}$. a, Sequence of catalyst silylation and nitronate addition leading to ion pair 3e-TBS-1b. b, ${ }^{31}$ P NMR traces corresponding to the respective steps in a (all measurements conducted at $193 \mathrm{~K}$; see Supplementary Figs. 4 and 5 for further details). c, DFT structure of ion pair 3e-TBS-1b. Red, oxygen; blue, nitrogen; black, carbon; white, hydrogen; orange, phosphorous; green, fluorine; yellow, sulfur.

to a practical and useful method to synthesize previously unknown $N$-Boc $\beta^{3}$-amino acid methyl esters on a multi-gram scale with high yields and excellent enantioselectivities, starting from simple commercially available nitroalkanes. These findings implicate the high synthetic potential of silyl nitronates as overlooked electrophilic substrates for asymmetric catalysis.

\section{Methods}

General procedure for the catalytic asymmetric addition of silyl ketene acetals to silyl nitronates. In an oven-dried GC vial with septum, the respective catalyst $(4.0-4.5 \mathrm{mg}, 2.5 \mathrm{~mol} \%)$ was dissolved in toluene $(200 \mu \mathrm{l}, 0.50 \mathrm{M}$ with respect to the nitronate) and reacted with the silyl ketene acetal ( 2.0 equiv., $0.20 \mathrm{mmol}, 44 \mu \mathrm{l}$ ) for $10 \mathrm{~min}$ at room temperature to give the active silylium IDPi species. After transfer to a cryostat with the indicated temperature and stirring for $10 \mathrm{~min}$, a stock solution of the silyl nitronate ( 1.0 equiv., $0.50 \mathrm{M}$ in $n$-pentane, $200 \mu \mathrm{l}$ ) was added dropwise and the resulting reaction mixture was stirred for the indicated time period. Subsequently, the reaction was quenched by the addition of $\mathrm{NEt}_{3}$ and $\mathrm{MeOH}\left(200 \mu \mathrm{mmol}^{-1}\right.$ of silyl nitronate), stirred for $10 \mathrm{~min}$ at the indicated temperature and then allowed to warm up to room temperature. The crude reaction mixtures were directly purified by flash column chromatography using silica gel ( $4 \%$ methyl tert-butyl ether in hexanes, solid phase previously flushed with hexanes/EtOAc/NEt $18: 1: 1 \mathrm{v} / \mathrm{v} / \mathrm{v}$ ) to give the nitroso acetal products as colourless oils.

\section{Data availability}

Experimental procedures and characterization data are given in the Supplementary Information. Crystallographic data of $r a c-5 p$ can be accessed via the Cambridge Crystallographic Data Centre (CCDC 2041572). Further data can be obtained from the corresponding author upon request.

Received: 17 July 2020; Accepted: 25 October 2021;

Published online: 2 December 2021

\section{References}

1. Mukaiyama, T., Narasaka, K. \& Banno, K. New aldol type reaction. Chem. Lett. 2, 1011-1014 (1973).

2. Kashutina, M. V., Ioffe, S. L. \& Tartakovskii, V. A. New possibilities for the use of nitroparaffins in organic synthesis. Dokl. Akad. Nauk. 218, 607-610 (1974).
3. Colvin, E. W. \& Seebach, D. Silyl nitronates: improved nitro-aldol reactions and reductive routes to 2-aminoalcohols. J. Chem. Soc. Chem. Commun. 689-691 (1978)

4. Colvin, E. W. et al. Synthesis, properties, and crystal structure of silyl nitronates (silyl esters of aci-nitroalkanes): towards the $\mathrm{S}_{\mathrm{N}} 2$ reaction path with retention of configuration at silicon. Helv. Chim. Acta 63, 697-710 (1980).

5. Sharma, S. C. \& Torssell, K. Silyl nitronates in organic synthesis. Routes to heterocycles. Acta Chem. Scand. 33b, 379-383 (1979).

6. Andersen, S. H. et al. Silyl nitronates in organic synthesis. Routes to heterocycles and cyclopentanoids. synthesis of allethrolone and calythrone. Acylation and cyanohydroxylation of double bonds. An exploratory study. Acta Chem. Scand. 36b, 1-14 (1982).

7. Knudsen, K. R., Risgaard, T., Nishiwaki, N., Gothelf, K. V. \& Jørgensen, K. A. The first catalytic asymmetric aza-Henry reaction of nitronates with imines: a novel approach to optically active $\beta$-nitro- $\alpha$-amino acid- and $\alpha, \beta$-diamino acid derivatives. J. Am. Chem. Soc. 123, 5843-5844 (2001).

8. Risgaard, T., Gothelf, K. V. \& Jørgensen, K. A. Catalytic asymmetric Henry reactions of silyl nitronates with aldehydes. Org. Biomol. Chem. 1, 153-156 (2002).

9. Ooi, T., Doda, K. \& Maruoka, K. Highly enantioselective michael addition of silyl nitronates to $\alpha, \beta$-unsaturated aldehydes catalyzed by designer chiral ammonium bifluorides: efficient access to optically active $\gamma$-nitro aldehydes and their enol silyl ethers. J. Am. Chem. Soc. 125, 9022-9023 (2003).

10. Ooi, T., Doda, K. \& Maruoka, K. Designer chiral quaternary ammonium bifluorides as an efficient catalyst for asymmetric nitroaldol reaction of silyl nitronates with aromatic aldehydes. J. Am. Chem. Soc. 125, 2054-2055 (2003).

11. Wilson, J. E., Casarez, A. D. \& MacMillan, D. W. C. Enantioselective aldehyde $\alpha$-nitroalkylation via oxidative organocatalysis. J. Am. Chem. Soc. 131, 11332-11334 (2009).

12. Tishkov, A. A. et al. $\mathrm{Me}_{3} \mathrm{SiBr}$-mediated intramolecular cyclization of $\gamma$-functionalized trimethylsilyl nitronates. Tetrahedron Lett. 40, 5075-5078 (1999).

13. Tishkov, A. A. et al. Novel $\mathrm{Me}_{3} \mathrm{Si}$-mediated intramolecular cyclisation/[4+2] cyclofragmentation of $\beta$-substituted $\gamma$-nitro ketones. Eur. J. Org. Chem. 2000, 3229-3233 (2000).

14. Smirnov, V. O. et al. New $\mathrm{C}-\mathrm{C}$ coupling reaction of cyclic nitronates with carbon nucleophiles. Umpolung of the conventional reactivity of nitronates. J. Org. Chem. 69, 8485-8488 (2004).

15. Smirnov, V. O., Sidorenkov, A. S., Khomutova, Y. A., Ioffe, S. L. \& Tartakovsky, V. A. Five-membered cyclic nitronates in C-C coupling with 1-(tert-butyldimethylsilyloxy)-1-methoxyethylene. Eur. J. Org. Chem. 2009, 3066-3074 (2009). 
16. Mikhaylov, A. A. et al. 3-Halomethylated cyclic nitronates: synthesis and nucleophilic substitution. Tetrahedron 67, 4584-4594 (2011).

17. Smirnov, V. O., Khomutova, Y. A., Tartakovsky, V. A. \& Ioffe, S. L. C-C coupling of acyclic nitronates with silyl ketene acetals under silyl triflate catalysis: reactivity umpolung of aliphatic nitro compounds. Eur. J. Org. Chem. 2012, 3377-3384 (2012).

18. Mikhaylov, A. A. et al. Stereoselective amine addition to six-membered cyclic nitronates promoted by silyl triflate. Eur. J. Org. Chem. 2013, 5670-5677 (2013).

19. Mikhaylov, A. A., Khomutova, Y. A., Arkhipov, D. E., Korlyukov, A. A. \& Ioffe, S. L. ButMe ${ }_{2}$ SiOTf-promoted cyanosilylation of six-membered cyclic nitronates with trialkylsilyl cyanides or tert-butyl isocyanide 1. Mendeleev Commun. 24, 374-376 (2014).

20. Zhmurov, P. A. et al. Divergent reactivity of in situ generated metal azides: reaction with $\mathrm{N}, \mathrm{N}$-bis(oxy)enamines as a case study. Chemistry $\mathbf{2 3}$, 4570-4578 (2017).

21. Matviitsuk, A. et al. Unanticipated silyl transfer in enantioselective $\alpha, \beta$-unsaturated acyl ammonium catalysis using silyl nitronates. Org. Lett. 22, 335-339 (2019).

22. Gatzenmeier, T. et al. Asymmetric Lewis acid organocatalysis of the Diels-Alder reaction by a silylated C-H acid. Science 351, 949-952 (2016).

23. Kaib, P. S. J., Schreyer, L., Lee, S., Properzi, R. \& List, B. Extremely active organocatalysts enable a highly enantioselective addition of allyltrimethylsilane to aldehydes. Angew. Chem. Int. Ed. 55, 13200-13203 (2016).

24. Bae, H. Y. et al. Approaching sub-ppm-level asymmetric organocatalysis of a highly challenging and scalable carbon-carbon bond forming reaction. Nat. Chem. 10, 888-894 (2018).

25. Gatzenmeier, T. et al. Scalable and highly diastereo- and enantioselective catalytic Diels-Alder reaction of $\alpha, \beta$-unsaturated methyl esters. J. Am. Chem. Soc. 140, 12671-12676 (2018).

26. Gatzenmeier, T., Kaib, P. S. J., Lingnau, J. B., Goddard, R. \& List, B. The catalytic asymmetric Mukaiyama-Michael reaction of silyl ketene acetals with $\alpha, \beta$-unsaturated methyl esters. Angew. Chem. Int. Ed. 57, 2464-2468 (2018).

27. Schreyer, L. et al. Confined acids catalyze asymmetric single aldolizations of acetaldehyde enolates. Science 362, 216-219 (2018).

28. Schreyer, L., Properzi, R. \& List, B. IDPi catalysis. Angew. Chem. Int. Ed. 58, 12761-12777 (2019).

29. Mitschke, B., Turberg, M. \& List, B. Confinement as a unifying element in selective catalysis. Chem 6, 2515-2532 (2020).

30. Gao, X. \& Kagan, H. B. One-pot multi-substrate screening in asymmetric catalysis. Chirality 10, 120-124 (1998).

31. Kim, H. et al. A multi-substrate screening approach for the identification of a broadly applicable Diels-Alder catalyst. Nat. Commun. 10, 770 (2019).

32. Cheng, R. P., Gellman, S. H. \& DeGrado, W. F. $\beta$-Peptides: from structure to function. Chem. Rev. 101, 3219-3232 (2001).

33. Hsiao, Y. et al. Highly efficient synthesis of $\beta$-amino acid derivatives via asymmetric hydrogenation of unprotected enamines. J. Am. Chem. Soc. 126, 9918-9919 (2004).

34. Hansen, K. B. et al. Highly efficient asymmetric synthesis of sitagliptin. J. Am. Chem. Soc. 131, 8798-8804 (2009).

35. Savile, C. K. et al. Biocatalytic asymmetric synthesis of chiral amines from ketones applied to sitagliptin manufacture. Science 329, 305-309 (2010).

36. Denmark, S. E., Guagnano, V. \& Vaugeois, J. Studies on the reduction and hydrolysis of nitroso acetals. Can. J. Chem. 79, 1606-1616 (2001).
37. Khomutova, Y. A., Smirnov, V. O., Mayr, H. \& Ioffe, S. L. Thermodynamic stability and reactivity of silylated bis(oxy)iminium ions. J. Org. Chem. 72, 9134-9140 (2007).

\section{Acknowledgements}

Generous support from the Max Planck Society, the Deutsche Forschungsgemeinschaft (Leibniz Award to B.L. and Cluster of Excellence Ruhr Explores Solvation, RESOLV), Fonds der Chemischen Industrie (Kekulé Fellowship to B.M.) and the European Research Council (Advanced Grant agreement number 694228 'C-H Acids for Organic Synthesis, CHAOS') are gratefully acknowledged. We are grateful to M. Leutzsch for his assistance with NMR spectroscopy.

\section{Author contributions}

C.K.D. and B.L. designed this study. S.D., B.M. and C.K.D. conducted the experiments. B.L. oversaw the project. S.D., B.M., C.K.D. and B.L. wrote the manuscript. S.D., B.M and C.K.D. wrote the Supplementary Information. I.H. and G.B. carried out the electronic structure calculations.

\section{Funding}

Open access funding provided by Max Planck Society.

\section{Competing interests}

A patent WO2017037141 (A1) filed by the Max-Planck-Institut für Kohlenforschung and B.L. covers the IDPi catalyst class and its applications in asymmetric synthesis. The other authors declare no competing interests.

\section{Additional information}

Supplementary information The online version contains supplementary material available at https://doi.org/10.1038/s41929-021-00714-x.

Correspondence and requests for materials should be addressed to Benjamin List.

Peer review information Nature Catalysis thanks Vishnu Ashok Adole, Peng Jiao, Herbert Mayr and the other, anonymous, reviewer(s) for their contribution to the peer review of this work.

Reprints and permissions information is available at www.nature.com/reprints. Publisher's note Springer Nature remains neutral with regard to jurisdictional claims in published maps and institutional affiliations.

\section{(i) Open Access This article is licensed under a Creative Commons}

Attribution 4.0 International License, which permits use, sharing, adaptation, distribution and reproduction in any medium or format, as long as you give appropriate credit to the original author(s) and the source, provide a link to the Creative Commons license, and indicate if changes were made. The images or other third party material in this article are included in the article's Creative Commons license, unless indicated otherwise in a credit line to the material. If material is not included in the article's Creative Commons license and your intended use is not permitted by statutory regulation or exceeds the permitted use, you will need to obtain permission directly from the copyright holder. To view a copy of this license, visit http://creativecommons. org/licenses/by/4.0/.

(c) The Author(s) 2021 